\title{
İki Farklı Lokasyona ait Altın Otunun (Helichrysum arenarium) Uçucu Bileşenlerinin Belirlenmesi ve Karşılaştırılması
}

\author{
Determination and Comparison of Volatile Compounds of Gold Grass (Helichrysum \\ arenarium) from Two Different Locations
}

\author{
Adil UMAZ ${ }^{* 1, a}$, Kader UMAZ ${ }^{2, b}$ \\ ${ }^{I}$ Mardin Artuklu Üniversitesi, Sağllk Hizmetleri Meslek Yüksekokulu, 47200, Mardin \\ ${ }^{2}$ Dicle Üniversitesi, Fen Fakültesi, Kimya Bölümü, 21280, Diyarbakır
}

\author{
• Geliş tarihi / Received: 18.09 .2019 •Düzeltilerek geliş tarihi / Received in revised form: 30.04 .2020 • Kabul tarihi / Accepted: 04.05 .2020
}

\begin{abstract}
Öz
Bu çalışmada, 2019 yılı Haziran-Ağustos ayında iki farklı bölgede toplanan Altın Otunun (Helichrysum arenarium) Katı Faz Mikro Ekstraksiyon (SPME) yöntemi kullanılarak uçucu bileşenleri Gaz Kromatografisi-Kütle Spektroskopisi (GC-MS) ile belirlendi. Bitlis Nemrut Krater Gölü çevresindeki Altın Otu örneğinde toplam 21 adet uçucu bileşen tespit edilirken, Giresun'un Şebinkarahisar İlçesi'nin dağlık bölgelerindeki Altın Otu örneğinde toplam 33 adet uçucu bileşen tespit edildi. Bitlis Nemrut Krater Gölü çevresindeki Altın Otunda $\alpha$-sedren (\%26.65), $\alpha$-pinen (\%14.97), $\alpha$-humulen (\%10.65), aromadendren (\%6.79), $\alpha$-kurkumen (\%6.31), germakren B (\%4.43), $\alpha$-kadinen (\%3.82), ökaliptol (\%3.57), $\alpha$-duprezianen (\%3.57) ve limonen (\%2.69) uçucu ana bileşen olarak tespit edilirken, Giresun Şebinkarahisar İlçesinin dağlık alanlarındaki Altın Otuna ait örnekte $\alpha$-pinen (\%47.63), $\alpha$-himakhalen (\%17.01), $\alpha$-humulen (\%5.21), $\delta$-kadinen (\%4.98), $\gamma$-kadinen (\%4.01) ve ökaliptol (\%3.46) uçucu ana bileşen olarak tespit edildi.
\end{abstract}

Anahtar kelimeler: Helichrysum arenarium, SPME/GC-MS, Uçucu Bileşenler

\begin{abstract}
In this study, volatile components by using Solid Phase Micro Extraction (SPME) method of Gold Grass (Helichrysum arenarium) collected in two different regions in June-August 2019 were determined by Gas Chromatography-Mass Spectroscopy $(G C-M S)$. While A total of 21 volatile components were detected in the sample of Golden Grass around Bitlis Nemrut Crater Lake, a total of 33 volatile components were detected in the sample of Golden Grass in the mountainous areas of Şebinkarahisar District of Giresun. While in the Golden Grass around Bitlis Nemrut Crater Lake $\alpha$-cedrene (26.65\%), $\alpha$-pinene (14.97\%), $\alpha$-humulene (10.65\%), aromadendrene $(6.79 \%), \alpha$-curcumene $(6.31 \%)$, germacrene B (4.43\%), $\alpha$-cadinene (3.82\%), eucalyptol (3.57\%), $\alpha$-duprezianene (3.57\%) and limonene (2.69\%) were detected as the volatile main component, in the Golden Grass sample in the mountainous areas of Shebinkarahisar District of Giresun $\alpha$-pinene (47.63\%), $\alpha$-himachalene (17.01\%), $\alpha$-humulene (5.21\%), $\delta$-cadinene (4.98\%), $\gamma$-cadinene (4.01\%) and eucalyptol (3.46\%) were detected as the volatile main component.
\end{abstract}

Keywords: Helichrysum arenarium, SPME/GC-MS, Volatile Components

\footnotetext{
*a Adil UMAZ, adilumaz@gmail.com, Tel: (0546) 49229 30, orcid.org/0000-0003-2438-5454

${ }^{\mathrm{b}}$ orcid.org/0000-0001-6039-3692
} 


\section{Giriş}

Helichrysum ismi, Yunanca'da güneş anlamına gelen "helios" ve altın anlamına gelen "chrysos" kelimelerinden türemiştir (Liu vd., 2019). Helichrysum arenarium bitkisi Asteraceae familyasına ait olup çok yıllık otsu bir bitkidir. Halk arasında altın otu, sonsuza dek süren, ölümsüz çiçek veya solmaz çiçek olarak bilinir (Czinner vd., 2000; Albayrak vd., 2010; Eroğlu vd., 2010; Moghadam vd., 2014; Figas vd., 2016; Liu vd., 2019).

Dünyada 600'ün üzerinde Helichrysum türü olup Amerika, İskandinavya, Atlantik, Avrupa, Balkanlar, Rusya, Sibirya, Kafkasya, Küçük Asya, Orta Asya, Moğolistan ve Çin de dahil olmak üzere geniş bir coğrafi bölgenin bozkırlarında, kumlu ve yarı sert topraklarda yetişen, $90 \mathrm{~cm}$ yüksekliğinde boylanan çok y1llık bir bitkidir (Jarzycka vd., 2013; Reidel vd., 2017; Kutluk vd., 2018). Helichrysum türü Türkiye florasında $15^{\prime} \mathrm{i}$ endemik olan ve Anadolu'da yaygın olarak bulunan 27 taksonla temsil edilmektedir (Albayrak vd., 2010).

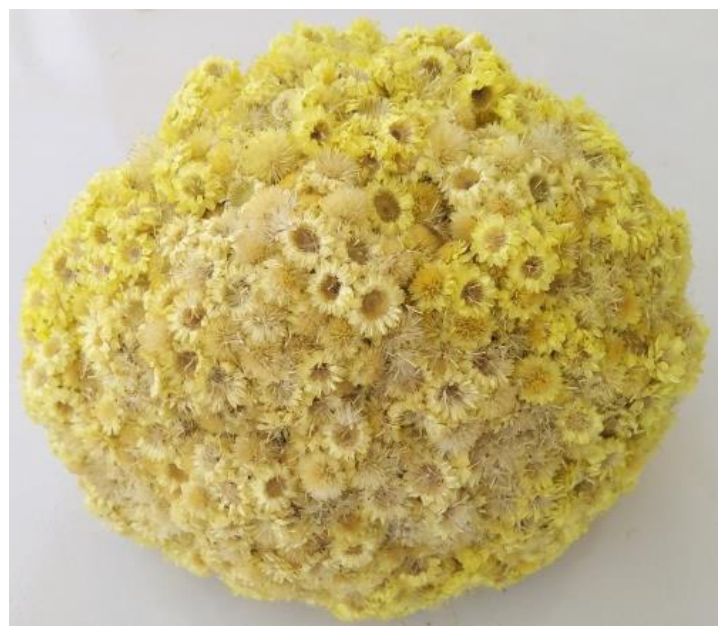

Şekil 1. Altın Otu (Helichrysum arenarium) bitkisi

Bazı farmakolojik veriler göre Helichrysum arenarium'un çiçeğinin flavonoidler, uçucu yağlar, yağ asitleri, karotenoidler, steroidler, ac1 maddeler, polifenoller, vitaminler, mineral tuzları, polisakaritler, glikozitler, kumarinler, kateşinler ve proantosiyanidinler de dahil olmak üzere fenolik bileşikler bakımından zengindir. Ayrıca astragalin, luteolin, kaempferol vb. gibi bileşenleri de içermektedir (Rančić vd., 2005; Eroğlu vd., 2010; Jarzycka vd., 2013; Liu vd., 2019).

Helichrysum arenarium'un çiçeği özellikle antibakteriyel, antiviral, antifungal, antienflamatuar, antiproliferatif, antimikrobiyal, antialerjik, antioksidan, antiradikal, kolinerjik, hepatoprotektif ve detoksifikasyon aktiviteleri de dahil olmak üzere birçok biyolojik aktiviteye sahiptir (Tepe vd., 2005; Mao vd., 2017; Liu vd., 2019). Halk hekimliğinde karaciğer ve safra kesesi rahatsızlıklarında, lumbago tedavisinde, mide ağrısı, astım, artrit bozuklukları, sistit ve sarılık tedavisinde, cilt enfeksiyonları, solunum ve sindirim sistemi bozuklukları, böbrek taş1 tedavisinde, üro-genital bozukluklar gibi çeşitli rahatsızlıkları tedavi etmek için kullanılmıştır. Ayrıca kozmetik endüstrisinde kokusu için uzun yıllardır kullanılmaktadır (Liu vd., 2019).

Ülkemizde Anadolu'da yaygın olarak bitkisel çay olarak kullanılır (Eroğlu vd., 2010). Güney Afrika'da, tüberkülozu ve ilgili semptomları tedavi etmek için ve geleneksel olarak Orta Avrupa'da antiseptik ve spazmolitik ilaçlar olarak kullanılır (Gradinaru vd., 2014; Moghadam vd., 2014; Reidel vd., 2017; Akin ve Saki, 2019).

Kat1 Faz Mikro Ekstraksiyon (SPME) yöntemini ilk olarak 1990 yılında uçucu bileşikleri analiz etmek için Arthur ve Pawliszyn tarafindan kullanılmıştır. SPME yöntemi sayesinde ekstraksiyon yapılmadan ve organik çözücü kullanılmadan katı numuneler analiz edilebilir. $\mathrm{Bu}$ yüzden SPME yöntemi diğer yöntemlerle karşılaştırıldığında kullanımı kolay, nispeten ucuz, çözücüsüz ve hassas bir tekniktir (Umaz vd., 2019). Bu çalışmada, Bitlis Nemrut Krater Gölü çevresindeki ve Giresun Şebinkarahisar İlçesinin dağlık alanlarına ait Altın Otunun (Helichrysum arenarium) uçucu bileşenlerinin SPME/GC-MS yöntemiyle belirlenmesi ve karşılaş̧ırması yapılmıştır.

\section{Materyal ve Yöntem}

\subsection{Bitki Örneklerinin Hazırlanması}

Çalı̧̧mada kullanılan iki farklı lokasyona ait Altın Otu örnekleri Haziran-Ağustos 2019 ayları arasında çiçeklenme döneminde Bitlis Nemrut Krater Gölü çevresinden ( $\left(38^{\circ} 37^{\prime} 10^{\prime \prime} \mathrm{K}\right),\left(42^{\circ} 14^{\prime}\right.$ $28^{\prime \prime}$ D), yüksseklik $\left.2.628 \mathrm{~m}\right)$ ve Giresun'un Şebinkarahisar İlçesinin dağlık alanlarından $\left(\left(40^{\circ}\right.\right.$ $\left.23^{\prime} 34^{\prime \prime} \mathrm{K}\right),\left(38^{\circ} 18^{\prime} 33^{\prime \prime} \mathrm{D}\right)$, yükseklik $\left.1.569 \mathrm{~m}\right)$ topland. Bitkilere ait örnekler Mardin Artuklu Üniversitesi Herbaryumuna getirilerek etiketlendi ve sakland. Bitki materyallerinin taksonomik teşhisi yapılarak doğrulandı. Ardından toplanan bitki örnekleri gölgelik ve hava akışının olduğu bir yerde kurutuldu. Elde edilen numuneler 10 mL'lik kapaklı vial içine konularak deneysel çalışmalarda kullanıldı. 


\subsection{Bitki Örneklerinin Analizi}

İki farklı lokasyona ait Altın Otu bitkisinin uçucu bileşenleri Gaz Kromatografisi-Kütle Spektrometresi (GC-MS) ile birleştirilmiş Katı Faz Mikro Ekstraksiyon (SPME) yöntemiyle belirlenmiş̧ir. SPME yöntemiyle, $10 \mathrm{~mL}$ 'lik vial içine $0.5 \mathrm{~g}$ kurutulmuş Altın Otu bitkisi konularak $25 \mathrm{dk}$. boyunca $60^{\circ} \mathrm{C}$ 'de bekletildi. Ardından SPME aparatı yardımıyla $100 \mu \mathrm{m}$ kalınlığında Polidimetilsilokzan (PDMS) kaplı slika fiber ile bitki örneklerinin uçucu bileşenleri absorbe edildi. Daha sonra GC-MS (Shimadzu QP-2020) cihazının kapiler kolonuna (Restek Rtx-5MS $30 \mathrm{~m}$ x $0.25 \mathrm{~mm}, 0.25 \mu \mathrm{m})$ enjekte edildi. Dedektör ve enjektör sıcaklıkları $250^{\circ} \mathrm{C}$ ve Firın sicaklığ $40^{\circ} \mathrm{C}^{\prime}$ de 2 dakika boyunca bekledikten sonra dakikada $4^{\circ} \mathrm{C}^{\prime}$ lik artışla $250^{\circ} \mathrm{C}^{\prime}$ ye ulaşılacak şekilde programlandı. İyonlaştırma türü olarak EI $(70 \mathrm{eV})$ ve taşıyıcı gaz olarak Helyum (1.2 $\mathrm{mL} / \mathrm{dk}$.) kullanıldı. Uçucu bileşenlerin belirlenmesinde Wiley, NIST Tutor (W9N11) ve FFNSC kütüphanesinden yararlanılmıştır. Alıkonma indis (Retention Indices (RI)) değerleri, C7-C30 alkan karışım standartlarına göre hesapland1.

\section{Bulgular ve Tartışma}

Bitlis Nemrut Krater Gölü çevresindeki Altın Otuna ait uçucu bileşenleri Tablo 1'de verilmiştir. Tablo 1'e bakıldığında Altın Otuna ait örnekte 21 adet uçucu bileşen tespit edildi. Tablo 1'de görüldüğü üzere $\alpha$-sedren $(\% 26.65), \alpha$-pinen (\%14.97), $\alpha$-humulen (\%10.65), aromadendren (\%6.79), $\alpha$-kurkumen (\%6.31), germakren B (\%4.43), $\alpha$-kadinen (\%3.82), ökaliptol (\%3.57), $\alpha$ duprezianen (\%3.57) ve limonen (\%2.69) uçucu ana bileşen olarak tespit edildi. Elde edilen verilerin kromatogramı Şekil 2'de görülmektedir.

Literatürde, Altın Otuna ait örnekte uçucu bileşenleri üzerine yapılan bir çalışmada ana bileşen olarak di-epi- $\alpha$-sedren (\%17.90), $\alpha$ ylangen (\%14.00), cyclosativen (\%11.90), limonen (\%11.40) ve $\alpha$-selinen (\%8.20) saptanmıştır (Rančić vd., 2005). Yapılan başka bir çalışmada Altın Otuna ait örnekte $\beta$-spathulenol (\%19.96), $\alpha$-bisabolol (\%10.24), ledol (\%10.02), aromadendren (\%5.15) ve $\alpha$-eudesmol (\%4.29) saptanmıştır (Liu vd., 2019). Ayrıca Altın Otunun çiçek ve yapraklarından elde edilen örnekte uçucu bileşenleri üzerine yapılan bir çalışmada $\beta$-pinen (\%55.20), $\alpha$-pinen (\%15.80) ve limonen (\%5.20) saptanmıştır (Reidel vd., 2017). Literatüre bakıldığında Bitlis Nemrut Krater Gölü çevresindeki Altın Otuna ait uçucu ana bileşenlerinin benzer olduğu görülmektedir.

Bitlis Nemrut Krater Gölü çevresindeki Altın Otuna ait \%1.18 Ester bileşikleri, \%0.66 Asit bileşikleri, \%66.12 Seskiterpen bileşikleri, \%23.35 Monoterpen bileşikleri ve \%8.69 Diğer bileşikler olduğu tespit edildi. Ayrıca, toplam terpen bileşikleri \%89.47 olarak tespit edildi. Literatürde, Altın Otun bitkisinin yapraklarından elde edilen örnekte \%66.20 Seskiterpen bileşikleri ve \%20.01 Monoterpen bileşiklerinin olduğu saptanmıştır (Judžentienė vd., 2019). Judzentiene ve Butkiene 2006 yılında yaptığı bir çalışmada, Altın Otunun Monoterpen ve Oksijenli Monoterpen bileşiklerinin \%4.0-13.9 arasında ve Seskiterpen bileşiklerinin ise \%24.7-71.2 arasında olduğunu belirtmiştir (Judzentiene ve Butkiene, 2006). Bir başka çalışmada, Altın Otu bitkisinin toplam Terpen bileşikleri \%82.83 olarak saptanmıştır (Liu vd., 2019). Literatüre baktığımızda deneysel çalışmada bulduğumuz değerlerin birbiriyle örtüştüğü görülmektedir.

Giresun Şebinkarahisar İlçesinin dağlik alanlarındaki Altın Otuna ait uçucu bileşenleri Tablo 2'de verilmiştir. Tablo 2'e bakıldığında Altın Otuna ait örnekte 33 adet uçucu bileşen tespit edildi. Tablo 2'de görüldüğü üzere $\alpha$-pinen (\%47.63), $\alpha$-himakhalen (\%17.01), $\alpha$-humulen $(\% 5.21), \delta$-kadinen $(\% 4.98), \gamma$-kadinen $(\% 4.01)$ ve ökaliptol (\%3.46) uçucu ana bileşen olarak tespit edildi. Elde edilen verilerin kromatogramı Şekil 3'de görülmektedir. Literatürde, Altın Otunun çiçek ve yapraklarından elde edilen örnekte uçucu bileşenleri üzerine yapılan bir çalışmada $\beta$-pinen (\%55.20) ve $\alpha$-pinen (\%15.80) saptanmıştır (Reidel vd., 2017). Radušienè ve ark., 2008 yılında yaptığı bir çalışmada, Altın Otunun çiçek kısımlarında trans-karyofilen ve $\delta$ kadinen bileşikleri uçucu ana bileşen olarak tespit edilmiştir (Radušiené ve Judžentienè, 2008). Yapılan başka bir çalışmada $\delta$-kadinen (\%9.00), $\gamma$ kadinen (\%5.50) ve $\alpha$-humulen (\%3.50) saptanmıştır (Judžentienè vd., 2019). Literatüre bakıldığında Giresun Şebinkarahisar İlçesinin dağlık alanlarındaki Altın Otuna ait uçucu ana bileşenlerinin benzer olduğu görülmektedir.

Giresun Şebinkarahisar İlçesinin dağlik alanlarındaki Altın Otuna ait \%0.64 Alkol bileşikleri, \%0.37 Ester bileşikleri, \%0.36 Asit bileşikleri, \%37.48 Seskiterpen bileşikleri, \%57.22 Monoterpen bileşikleri ve \%3.94 Diğer bileşikler olduğu tespit edildi. 
Tablo 1. Bitlis Nemrut Krater Gölü çevresine ait Altın Otunun uçucu bileşenleri

\begin{tabular}{|c|c|c|c|c|}
\hline \multicolumn{5}{|c|}{ Bitlis Nemrut Krater Gölü çevresindeki Altın Otu (Helichrysum arenarium) } \\
\hline No & Uçucu Bileșenler & R.Time & $\mathbf{R I}$ & $\%$ \\
\hline 1 & $\alpha$-pinen & 9.65 & 931 & 14.97 \\
\hline 2 & kampen & 10.20 & 953 & 1.40 \\
\hline 3 & limonen & 13.31 & 1030 & 2.69 \\
\hline 4 & ökaliptol & 13.43 & 1033 & 3.57 \\
\hline 5 & $\alpha$-terpinen & 15.70 & 1018 & 0.72 \\
\hline 6 & pelargonik asit & 22.43 & 1281 & 0.66 \\
\hline 7 & $\alpha$-kopaen & 26.35 & 1376 & 2.59 \\
\hline 8 & tetradekan & 26.98 & 1399 & 0.67 \\
\hline 9 & $\alpha$-duprezianen & 27.30 & 1424 & 3.57 \\
\hline 10 & aromadendren & 27.84 & 1439 & 6.79 \\
\hline 11 & $\alpha$-gurjunen & 28.85 & 1409 & 1.69 \\
\hline 12 & $\alpha$-humulen & 28.97 & 1450 & 10.65 \\
\hline 13 & germakren B & 29.16 & 1481 & 4.43 \\
\hline 14 & $\alpha$-sedren & 29.72 & 1498 & 26.65 \\
\hline 15 & $\alpha$-kurkumen & 29.82 & 1501 & 6.31 \\
\hline 16 & $\beta$-selinen & 30.03 & 1485 & 0.95 \\
\hline 17 & 10beta-H-kadina-1 (6), 4-dien & 30.40 & 1520 & 2.41 \\
\hline 18 & nopil asetat & 30.45 & 1529 & 1.18 \\
\hline 19 & $\gamma$-kadinen & 30.91 & 1513 & 1.26 \\
\hline 20 & $\delta$-kadinen & 31.17 & 1522 & 3.82 \\
\hline 21 & hekzadekan & 33.32 & 1559 & 3.02 \\
\hline \multicolumn{3}{|c|}{ \% Toplam Tanımlanmıș Bileşikler } & & 100.00 \\
\hline \multicolumn{3}{|c|}{ \%Ester Bileşikleri } & & 1.18 \\
\hline \multicolumn{3}{|c|}{ \% Asit Bileşikleri } & & 0.66 \\
\hline \multicolumn{3}{|c|}{ \%Seskiterpen Bileşikleri } & & 66.12 \\
\hline \multicolumn{3}{|c|}{ \%Monoterpen Bileşikleri } & & 23.35 \\
\hline \multicolumn{3}{|c|}{ \% Diğer Bileșikler } & & 8.69 \\
\hline
\end{tabular}

R.Time: Alıkonma zamanı, RI: Alıkonma indisi

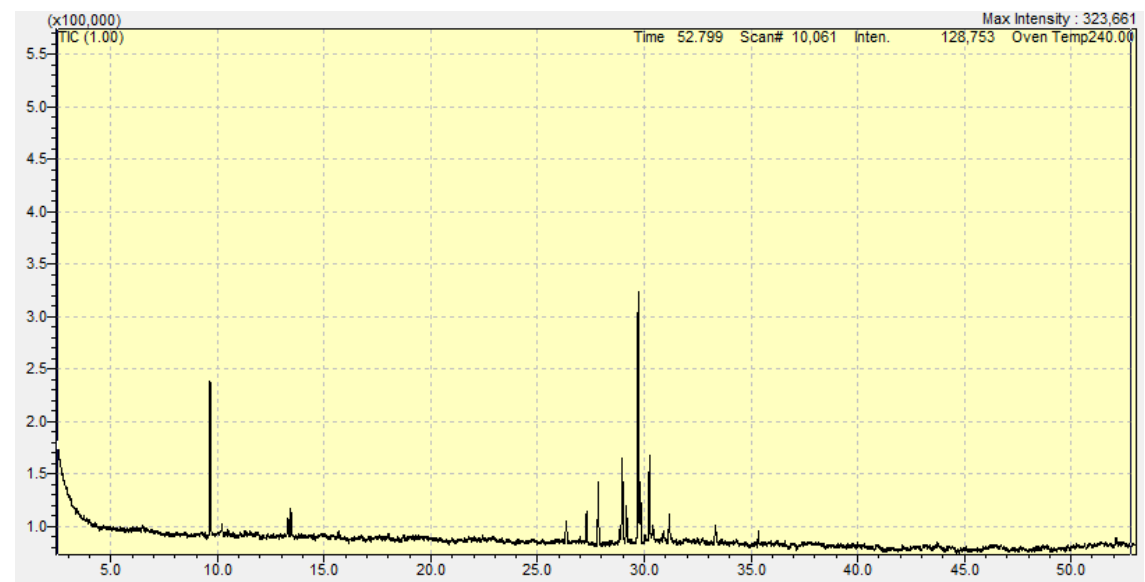

Şekil 2. Bitlis Nemrut Krater Gölü çevresindeki Altın Otuna ait GC-MS/SPME kromatogramı

Ayrıca, Giresun Şebinkarahisar İlçesinin dağlık alanlarındaki Altın Otu bitkisinin toplam terpen bileşikleri \%94.70 olarak tespit edildi.

Literatürde, Altın Otun bitkisinin yapraklarından elde edilen örnekte \%12.80 Seskiterpen bileşikleri ve \%85.10 Monoterpen bileşiklerinin olduğu saptanmıştır. Altın Otu bitkisinin toplam terpen bileşikleri \%94.00 olarak saptanmıştır (Reidel vd., 2017). Başka bir çalışmada, Altın Otuna ait Monoterpen bileşikleri \%15.0-93.1 arasında ve seskiterpen bileşikleri ise \%1.1-25.5 arasında olduğu bildirilmiştir (Öztürk vd., 2014). Literatüre baktığımızda deneysel çalışmada bulduğumuz değerlerin birbiriyle örtüştüğü görülmektedir. İki farklı lokasyona ait Altı Otu bitkisi karşılaştırıldığında Giresun Şebinkarahisar İlçesinin dağlı alanlarındaki Altın Otunun Monoterpen bileşiklerinin yüzdesi Bitlis Nemrut Krater Gölü çevresindeki Altın Otununkiden daha yüksek olduğu tespit edildi. 
Tablo 2. Giresun Şebinkarahisar İlçesinin dağlık alanlarına ait Altın Otunun uçucu bileşenleri

\begin{tabular}{|c|c|c|c|c|}
\hline \multicolumn{5}{|c|}{ Giresun Şebinkarahisar İlçesinin dağlık alanlarındaki Altın Otu (Helichrysum arenarium) } \\
\hline No & Uçucu Bileșenleri & R.Time & RI & $\%$ \\
\hline $\mathbf{1}$ & kapril alkol & 5.04 & 902 & 0.20 \\
\hline 2 & 3-metil pentanol & 6.93 & 921 & 0.30 \\
\hline 3 & $\alpha$-pinen & 9.67 & 931 & 47.63 \\
\hline 4 & $\delta$-3-karen & 10.16 & 957 & 1.81 \\
\hline 5 & $\beta$-pinen & 11.29 & 980 & 0.92 \\
\hline 6 & Mirsen & 11.89 & 992 & 0.25 \\
\hline 7 & $\alpha$-terpinen & 12.85 & 1018 & 0.20 \\
\hline 8 & p-simen & 13.16 & 1026 & 0.26 \\
\hline 9 & Limonen & 13.32 & 1030 & 1.29 \\
\hline 10 & Ökaliptol & 13.42 & 1033 & 3.46 \\
\hline 11 & (E)-beta-osimen & 14.11 & 1060 & 0.37 \\
\hline 12 & $\gamma$-terpinen & 14.52 & 1061 & 0.65 \\
\hline 13 & Terpinolen & 15.68 & 1087 & 0.22 \\
\hline 14 & linalil format & 17.16 & 1140 & 0.10 \\
\hline 15 & İsoborneol & 18.72 & 1180 & 0.14 \\
\hline 16 & terpinen-4-ol & 19.10 & 1177 & 0.16 \\
\hline 17 & hekzil-3-methil-bütanoat & 21.31 & 1251 & 0.14 \\
\hline 18 & $\alpha$-amorfen & 26.02 & 1385 & 0.27 \\
\hline 19 & $\alpha$-kopaen & 26.34 & 1376 & 2.91 \\
\hline 20 & $\alpha$-himakhalen & 27.85 & 1450 & 17.01 \\
\hline 21 & aromadendren & 28.48 & 1439 & 0.28 \\
\hline 22 & $\alpha$-gurjunen & 27.51 & 1409 & 0.33 \\
\hline 23 & $\alpha$-humulen & 28.97 & 1450 & 5.21 \\
\hline 24 & alloaromadendren & 29.22 & 1462 & 2.36 \\
\hline 25 & $\beta$-selinen & 30.05 & 1485 & 0.09 \\
\hline 26 & $\alpha$-bulnesen & 30.32 & 1517 & 0.29 \\
\hline 27 & 10beta-H-kadina-1 (6), 4-dien & 29.60 & 1520 & 0.52 \\
\hline 28 & $\alpha$-muurolen & 30.45 & 1500 & 1.76 \\
\hline 29 & $\gamma$-kadinen & 30.91 & 1513 & 4.01 \\
\hline 30 & $\delta$-kadinen & 31.18 & 1522 & 4.98 \\
\hline 31 & karyofillen oksit & 33.11 & 1609 & 0.35 \\
\hline 32 & epi- $\alpha$-muurolol & 34.04 & 1640 & 0.89 \\
\hline 33 & guaiyl asetat & 34.42 & 1654 & 0.13 \\
\hline & m Tanımlanmış Bileşikler & & & 99.49 \\
\hline & Bileşikleri & & & 0.64 \\
\hline & Bileşikleri & & & 0.37 \\
\hline & ileşikleri & & & 0.35 \\
\hline & erpen Bileşikleri & & & 37.48 \\
\hline & terpen Bileşikleri & & & 57.22 \\
\hline$\% \mathrm{I}$ & Bileșikler & & & 3.94 \\
\hline
\end{tabular}

R.Time: Alıkonma zamanı, RI: Alıkonma indisi

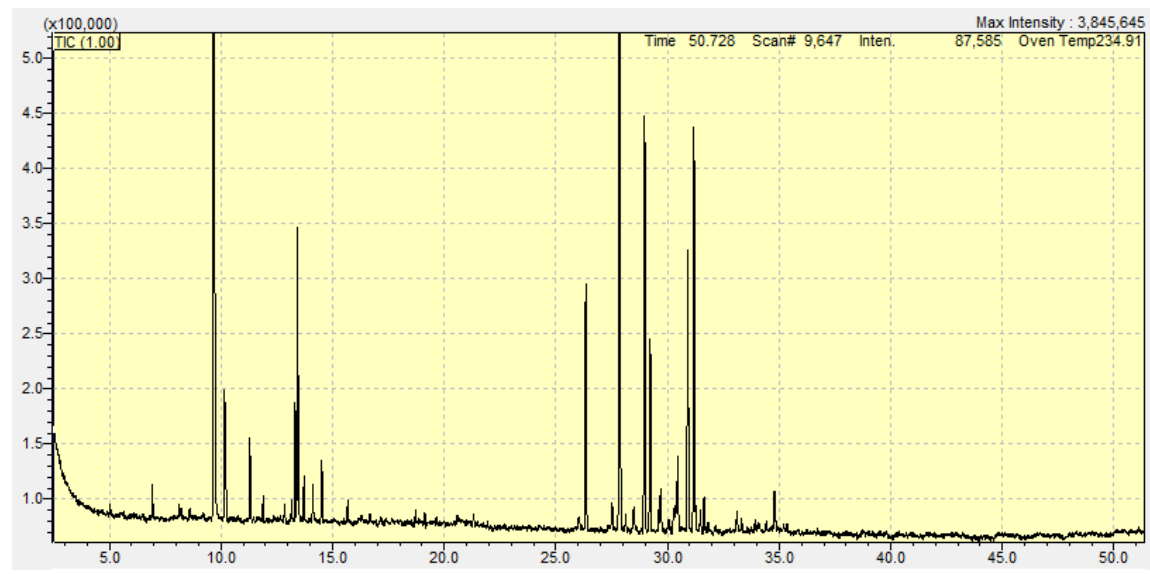

Şekil 3. Giresun Şebinkarahisar İlçesinin dağlık alanlarındaki Altın Otuna ait GC-MS/SPME kromatogramı 
Bitlis Nemrut Krater Gölü çevresindeki Altın Otunun Seskiterpen bileşiklerinin yüzdesi ise Giresun Şebinkarahisar İlçesinin dağlık alanlarındaki Altın Otununkiden daha yüksek olduğu tespit edildi.

Tablo 3. Bitlis Nemrut Krater Gölü çevresine ait altın Otu ve Giresun Şebinkarahisar İlçesinin dağlık alanlarına ait altın Otunun uçucu bileşenlerinin karşılaştırılması

\begin{tabular}{|c|c|c|c|c|c|c|c|}
\hline \multirow[b]{2}{*}{ No } & \multirow[b]{2}{*}{ Uçucu Bileşenler } & \multicolumn{3}{|c|}{ B. N. K. G. Ç. Altın Otu } & \multicolumn{3}{|c|}{ G. Ş. İ. D. A. Altın Otu } \\
\hline & & R. Time & RI & $\%$ & R. Time & RI & $\%$ \\
\hline 1 & kapril alkol & - & - & - & 5.04 & 902 & 0.20 \\
\hline 2 & 3-metil pentanol & - & - & - & 6.93 & 921 & 0.30 \\
\hline 3 & $\alpha$-pinen & 9.65 & 931 & 14.97 & 9.67 & 931 & 47.63 \\
\hline 4 & Kamfen & 10.20 & 953 & 1.40 & - & - & - \\
\hline 5 & $\delta$-3-karen & - & - & - & 10.16 & 957 & 1.81 \\
\hline 6 & $\beta$-pinen & - & - & - & 11.29 & 980 & 0.92 \\
\hline 7 & Mirsen & - & - & - & 11.89 & 992 & 0.25 \\
\hline 8 & $\alpha$-terpinen & 15.70 & 1018 & 0.72 & 12.85 & 1018 & 0.20 \\
\hline 9 & $\mathrm{p}$-simen & - & - & - & 13.16 & 1026 & 0.26 \\
\hline 10 & Limonen & 13.31 & 1030 & 2.69 & 13.32 & 1030 & 1.29 \\
\hline 11 & Ökaliptol & 13.43 & 1033 & 3.57 & 13.42 & 1033 & 3.46 \\
\hline 12 & (E)-beta-osimen & - & - & - & 14.11 & 1060 & 0.37 \\
\hline 13 & $\gamma$-terpinen & - & - & - & 14.52 & 1061 & 0.65 \\
\hline 14 & terpinolen & - & - & - & 15.68 & 1087 & 0.22 \\
\hline 15 & linalil format & - & - & - & 17.16 & 1140 & 0.10 \\
\hline 16 & isoborneol & - & - & - & 18.72 & 1180 & 0.14 \\
\hline 17 & terpinen-4-ol & - & - & - & 19.10 & 1177 & 0.16 \\
\hline 18 & hekzil-3-methil-bütanoat & - & - & - & 21.31 & 1251 & 0.14 \\
\hline 19 & pelargonik asit & 22.43 & 1281 & 0.66 & - & - & - \\
\hline 20 & $\alpha$-amorfen & - & - & - & 26.02 & 1385 & 0.27 \\
\hline 21 & $\alpha$-kopaen & 26.35 & 1376 & 2.59 & 26.34 & 1376 & 2.91 \\
\hline 22 & tetradekan & 26.98 & 1399 & 0.67 & - & - & - \\
\hline 23 & $\alpha$-duprezianen & 27.30 & 1424 & 3.57 & - & - & - \\
\hline 24 & $\alpha$-gurjunen & 28.85 & 1409 & 1.69 & 27.51 & 1409 & 0.33 \\
\hline 25 & $\alpha$-himakhalen & - & - & - & 27.85 & 1450 & 17.01 \\
\hline 26 & aromadendren & 27.84 & 1439 & 6.79 & 28.48 & 1439 & 0.28 \\
\hline 27 & $\alpha$-humulen & 28.97 & 1450 & 10.65 & 28.97 & 1450 & 5.21 \\
\hline 28 & germakren B & 29.16 & 1481 & 4.43 & - & - & - \\
\hline 29 & alloaromadendren & - & - & - & 29.22 & 1462 & 2.36 \\
\hline 30 & 10beta-H-kadina-1 (6), 4-dien & 30.40 & 1520 & 2.41 & 29.60 & 1520 & 0.52 \\
\hline 31 & $\alpha$-sedren & 29.72 & 1498 & 26.65 & - & - & - \\
\hline 32 & $\alpha$-kurkumen & 29.82 & 1501 & 6.31 & - & - & - \\
\hline 33 & $\beta$-selinen & 30.03 & 1485 & 0.95 & 30.05 & 1485 & 0.09 \\
\hline 34 & $\alpha$-bulnesen & - & - & - & 30.32 & 1517 & 0.29 \\
\hline 35 & $\alpha$-muurolen & - & - & - & 30.45 & 1500 & 1.76 \\
\hline 36 & nopil asetat & 30.45 & 1529 & 1.18 & - & - & - \\
\hline 37 & $\gamma$-kadinen & 30.91 & 1513 & 1.26 & 30.91 & 1513 & 4.01 \\
\hline 38 & $\delta$-kadinen & 31.17 & 1522 & 3.82 & 31.18 & 1522 & 4.98 \\
\hline 39 & karyofillen oksit & - & - & - & 33.11 & 1609 & 0.35 \\
\hline 40 & hekzadekan & 33.32 & 1559 & 3.02 & - & - & - \\
\hline 41 & epi- $\alpha$-muurolol & - & - & - & 34.04 & 1640 & 0.89 \\
\hline 42 & guaiyl asetat & - & - & - & 34.42 & 1654 & 0.13 \\
\hline \multicolumn{2}{|c|}{ \% Toplam Tanımlanmıș Bileșikler } & & & 100.00 & & & 99.49 \\
\hline \multicolumn{2}{|c|}{ \%Alkol Bileşikleri } & & & - & & & 0.64 \\
\hline \multicolumn{2}{|c|}{ \%Ester Bileşikleri } & & & 1.18 & & & 0.37 \\
\hline \multicolumn{2}{|c|}{ \%Asit Bileşikleri } & & & 0.66 & & & 0.35 \\
\hline \multicolumn{2}{|c|}{ \%Seskiterpen Bileşikleri } & & & 66.12 & & & 37.48 \\
\hline \multicolumn{2}{|c|}{ \%Monoterpen Bileşikleri } & & & 23.35 & & & 57.22 \\
\hline \multicolumn{2}{|c|}{ \%Diğer Bileşikler } & & & 8.69 & & & 3.94 \\
\hline
\end{tabular}

R.Time: Alıkonma zamanı, RI: Alıkonma indisi, B. N. K. G. Ç.: Bitlis Nemrut Krater Gölü Çevresine ait, G. Ş. İ. D. A.: Giresun Şebinkarahisar İlçesinin Dağlık Alanlarına ait 


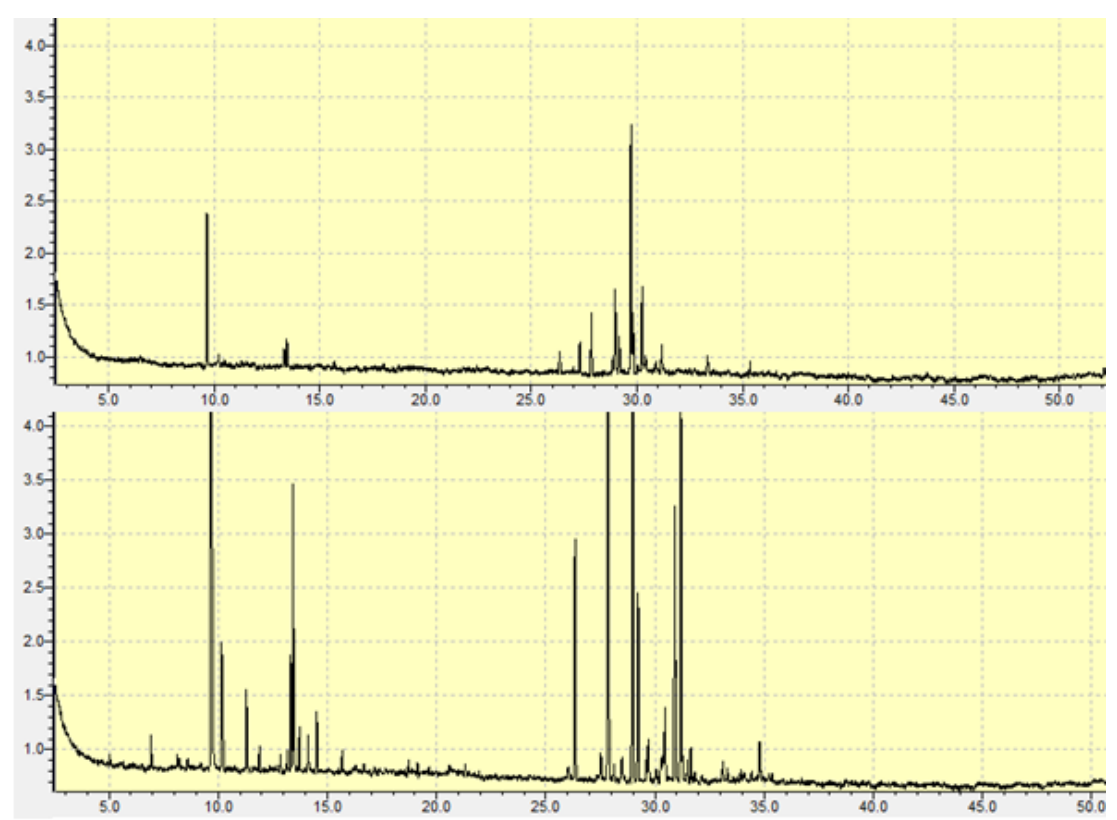

Şekil 4. Bitlis Nemrut Krater Gölü çevresindeki Altın Otu (A) ve Giresun Şebinkarahisar İlçesinin dağlık alanlarındaki Altın Otuna (B) ait GC-MS/SPME kromatogramların karşılaştırılması

Bitlis Nemrut Krater Gölü çevresine ait Altın Otu ile Giresun Şebinkarahisar İlçesinin dağlı alanlarına ait Altın Otunun uçucu bileşenlerinin karşılaştırıldığında Bitlis Nemrut Krater Gölü çevresine ait Altın Otu örneğinde 21 adet uçucu bileşeni varken, Giresun Şebinkarahisar İlçesinin dağlık alanlarına ait Altın Otu örneğinde ise 33 adet uçucu bileşeni tespit edildi. Tablo 3'e bakıldığında iki farklı lokasyona ait Altın Otunun toplamda 42 adet uçucu bileşenleri belirlendi. Yapılan SPME/GC-MS analizi sonucunda iki farklı lokasyona ait Altın Otu bitkisinin çakıştırılmış kromatogramı Şekil 4'te görülmektedir. Kromatogram incelendiğinde iki farklı yöre ait Altın Otunun 10-15 dakika ve 25-35 dakikalardaki alıkonma zamanları ve pik benzerliği örtüşmektedir. İki farklı lokasyona ait Altın Otunun uçucu bileşenlerinin farklı olması iklim ve coğrafi bölge farklılığından kaynaklandığını düşünmekteyiz. Kutluk vd., (2018) yılında yaptığı bir çalışmada bitkilerin kimyasal bileşimlerinin değişkenliğinin genetik, coğrafi ve iklimsel faktörlerle bağlantılı olduğu belirtilmektedir (Kutluk vd., 2018).

$\alpha$-pinen, monoterpen sınıfinda olup antimikrobiyal ve antiinflamatuar aktivite gösterdiği için geniş spektrumlu bir antibiyotik olarak işlev görmektedir. Ayrıca asetilkolin inhibitörü olarak da kullanilır. $\alpha$-pinen merhem ve kremlerde ana bileşen olarak da kullanılmıştır (Yaşar vd., 2017).

Limonen, monoterpen sınıfinın bir üyesi olup güzel ve keskin bir kokuya sahiptir. Bu yüzden temizlik ürünlerinde leke çıkarıcı olarak kullanılmaktadır. Ayrıca Limonen uçucu ana bileşeni, antibakteriyel ve antifungal aktiviye sahiptir (Umaz vd., 2019).

$\alpha$-humulen, humalan grubuna ait biyojenetik olarak ilişkili seskiterpenlerdir (Benelli vd., 2018). $\alpha$-humulen, kanser hücrelerine karşı ve in vivo çalışmalarda sitotoksik etkiye sahip oldukları bildirilmiştir (Pavithra vd., 2018).

Aromadendrenler, terpenler sinifinda olup ilk olarak okaliptüs ağacından izole edilmiştir. Ayrıca aromadendrenler antifungal, antibakteriyel, antiviral ve sitotoksik aktiviteler gibi çeşitli biyolojik aktivitelere sahip olduğu bildirilmiştir (Pavithra vd., 2018).

$\alpha$-sedren, çam veya selvi botanik ailelerinden türetilmiş, sedir ağacı yağlarından oluşan bir seskiterpendir. $\alpha$-sedren yeni bir obezite karşıtı ilaç olarak görülmesine rağmen farmakokinetik özellikleri hakkında sınırlı bilgi mevcuttur (Kim vd., 2015).

Ökaliptol, birçok bitkide, özellikle de okaliptüs türlerinde mevcut olan monoterpenoid sinıfinda olup antienflamatuar ve antioksidan aktiviteye sahip olduğu bildirilmiştir (Kennedy-feitosa vd., 2019).

$\alpha$-kurkumen, seskiterpen bileşik sınıfında olup antimikrobiyal aktiviteye sahip olduğu bildirilmiştir (Narjara vd., 2015). 


\section{Sonuç}

$\mathrm{Bu}$ çalışmada, iki farklı lokasyona ait Altın Otunun uçucu bileşenlerinin SPME/GC-MS yöntemiyle tespit edilip karşılaştırması yapılmıştır. Altın Otu çiçeğinin antibakteriyel, antiviral, antifungal, antienflamatuar, antimikrobiyal, antialerjik, antioksidan, antiradikal ve kolinerjik gibi biyolojik aktiviteye sahip olması nedeniyle bu bitkinin ilaç ham maddesi olarak kullanılabilir olduğunu gösterir.

Bitlis Nemrut Krater Gölü çevresindeki Altın Otu bitkisinin uçucu bileşenlerinden biri olan $\alpha$-sedren obezite karşitı yeni bir ilaç etken maddesi olarak kullanılması bu bitkinin obezite karşıtı bir ilaç olarak kullanılmasına olanak sağlar.

Giresun Şebinkarahisar İlçesinin dağlık alanlarındaki Altın Otu bitkisinin uçucu bileşenlerinden biri olan $\alpha$-pinen'in antimikrobiyal ve antiinflamatuar aktivite gösterdiği için bu bitki ilaç endüstrisinde geniş sepektrumlu bir antibiyotik olarak kullanılabilir olduğunu söyleyebiliriz.

\section{Kaynaklar}

Akin, M. ve Saki, N., 2019. Antimicrobial, DPPH Scavenging and Tyrosinase Inhibitory Activities of Thymus Vulgaris, Helichrysum arenarium and Rosa Damascena Mill. Ethanol Extracts by using TLC Bioautography and Chemical Screening Methods. Journal of Liquid Chromatography and Related Technologies, 42(7-8), 204-216.

Albayrak, S., Aksoy, A., Sağdiç, O. ve Budak, Ü., 2010. Phenolic Compounds and Antioxidant and Antimicrobial Properties of Helichrysum Species Collected from Eastern Anatolia Turkey. Turkish Journal of Biology, 34(4), 463473.

Benelli, G., Govindarajan, M., Rajeswary, M., Vaseeharan, B., Alyahya, S.A., Alharbi, N.S. ve Maggi, F., 2018. Insecticidal Activity of Camphene, Zerumbone and $\alpha$-humulene from Cheilocostus Speciosus Rhizome Essential Oil against the Old-World Bollworm, Helicoverpa armigera. Ecotoxicology and Environmental Safety, 148, 781-786.

Czinner, E., Lemberkovics, É., Bihátsi-Karsai, E., Vitányi, G. ve Lelik, L., 2000. Composition of the Essential Oil from the Inflorescence of Helichrysum arenarium (L.) Moench. Journal of Essential Oil Research, 12(6), 728-730.
Eroğlu, H.E., Hamzaoğlu, E., Budak, Ü., Aksoy, A. ve Albayrak, S., 2010. Cytogenetic Effects of Helichrysum arenarium in Human Lymphocytes Cultures. Turkish Journal of Biology, 34(3), 253-259.

Figas, A., Tomaszewska-Sowa, M., Sawilska, A. ve Keutgen, A.J., 2016. Improvement of in Vitro Propagation and Acclimation of Helichrysum arenarium L. Moench. Acta Scientiarum Polonorum, Hortorum Cultus, 15(4), 17-26.

Gradinaru, A.C., Silion, M., Trifan, A., Miron, A. ve Aprotosoaie, A.C., 2014. Helichrysum arenarium subsp. arenarium: Phenolic Composition and Antibacterial Activity against Lower Respiratory Tract Pathogens. Natural Product Research, 28(22), 2076-2080.

Jarzycka, A., Lewińska, A., Gancarz, R. ve Wilk, K.A., 2013. Assessment of Extracts of Helichrysum arenarium, Crataegus Monogyna, Sambucus Nigra in Photoprotective UVA and UVB; Photostability in Cosmetic Emulsions. Journal of Photochemistry and Photobiology B: Biology, 128, 50-57.

Judzentiene, A., ve Butkiene, R., 2006. Chemical Composition of the Essential Oils of Wild Helichrysum arenarium (L.) with Differently Colored Inflorescences from Eastern Lithuania. Journal of Essential Oil Research, 18(1), 80-83.

Judžentienè, A., Charkova, T. ve Misiūnas, A., 2019. Chemical Composition of the Essential Oils from Helichrysum arenarium (L.) Plants Growing in Lithuanian Forests. Journal of Essential Oil Research, 31(4), 305-311.

Kennedy-feitosa, E., Cattani-cavalieri, I., Valente, M., Biomédicas, I.D.C. ve Federal, U., 2019. Phytomedicine Eucalyptol Promotes Lung Repair in Mice Following Cigarette SmokeInduced Emphysema. Phytomedicine, 55, 7079.

Kim, T.H., Yoo, S.D., Lee, H.S., Lee, K.M., Seok, S.H., Kim, M.G. ve Shin, B.S., 2015. In Vivo Absorption and Disposition of $\alpha$-cedrene, a Sesquiterpene Constituent of Cedarwood Oil, in Female and Male Rats. Drug Metabolism and Pharmacokinetics, 30(2), 168-173.

Kutluk, I., Aslan, M., Orhan, I.E. ve Özçelik, B., 2018. Antibacterial, Antifungal and Antiviral Bioactivities of Selected Helichrysum Species. South African Journal of Botany, 119, 252-257.

Liu, X., Jing, X. ve Li, G., 2019. A Process to Acquire Essential Oil by Distillation Concatenated Liquid-Liquid Extraction and Flavonoids by Solid-Liquid Extraction Simultaneously from Helichrysum arenarium (L.) Moench Inflorescences under İonic Liquid-Microwave 
Mediated. Separation and Purification Technology, 209, 164-174.

Mao, Z., Gan, C., Zhu, J., Ma, N., Wu, L., Wang, L. ve Wang, X., 2017. Anti-atherosclerotic Activities of Flavonoids from the Flowers of Helichrysum arenarium L. Moench through the Pathway of Antiinflammation. Bioorganic and Medicinal Chemistry Letters, 27(12), 2812-2817.

Moghadam, H.D., Sani, A.M. ve Sangatash, M.M., 2014. Inhibitory Effect of Helichrysum arenarium Essential Oil on the Growth of Food Contaminated Microorganisms. Journal of Essential Oil-Bearing Plants, 17(5), 911-921.

Narjara, G., Pozzatti, P., Rigatti, F., Hörner, R., Alves, S.H., Augusto, C. ve Heinzmann, B.M., 2015. Antimicrobial evaluation of sesquiterpene $\alpha$ curcumene and Its Synergism with Imipenem. Journal of Microbiology, Biotechnology and Food Sciences, 4(5), 434-436.

Öztürk, B., Özek, G., Özek, T., Baser, K.H.C., 2014. Chemical Diversity in Volatiles of Helichrysum plicatum DC. Subspecies in Turkey. Records of Natural Products, 8(4), 373-384.

Pavithra, P.S., Mehta, A. ve Verma, R.S., 2018. Aromadendrene Oxide 2, Induces Apoptosis in Skin Epidermoid Cancer Cells through ROS Mediated Mitochondrial Pathway. Life Sciences, 197, 19-29.

Rančić, A., Soković, M., Vukojević, J., Simić, A., Marin, P., Duletić-Laušević, S. ve Djoković, D.,
2005. Chemical Composition and Antimicrobial Activities of Essential Oils of Myrrhis odorata (L.) scop, Hypericum perforatum $\mathrm{L}$ and Helichrysum arenarium (L.) Moench. Journal of Essential Oil Research, 17(3), 341-345.

Radušienè, J., ve Judžentienè, A., 2008. Volatile Composition of Helichrysum arenarium Field Accessions with Differently Coloured Inflorescences. Biologija, 54(2), 116-120.

Reidel, R.V.B., Cioni, P.L., Ruffoni, B., Cervelli, C. ve Pistelli, L., 2017. Aroma Profile and Essential Oil Composition of Helichrysum Species. Natural Product Communications, 12(9), 15071512.

Tepe, B., Sokmen, M., Askin Akpulat, H. ve Sokmen, A., 2005. In Vitro Antioxidant Activities of the Methanol Extracts of Four Helichrysum Species from Turkey. Food Chemistry, 90(4), 685-689.

Umaz, A., Baran, M.F., Güngören, M. ve Umaz, K., 2019. Mardin, Diyarbakır ve Gaziantep'te Güneşte Kurutulan Üzümlerin SPME/GC-MS Metoduyla Uçucu Bileşenlerinin Karşılaştırılması. Ejons (Internatıonal Journal on Mathematics, Engineering \& Natural Sciences), 9(3), 100-106.

Yaşar, S., Güler, G., Beram, A., Coşkun, D. ve Ozansoy, D., 2017. Acı Yavşan Otu (Artemisia absinthium L.) Yaprak Uçucu Bileşenleri. Mehmet Akif Ersoy Üniversitesi Fen Bilimleri Enstitüsü Dergisi. 8(2), 148-152. 